\title{
DEVELOPMENT OF THE STRUCTURAL AND FUNCTIONAL DESIGN OF THE LABORATORY BENCH FOR EXPERIMENTAL RESEARCH DIESEL GENERATOR SETS ON VARIABLE SPEED
}

\author{
Sergei Obuhov ${ }^{1, *}$, Igor Plotnikov ${ }^{1}$, Michael Surkov ${ }^{1}$, Lyudmila Sumarokova ${ }^{1}$, and \\ Kirill Savkin ${ }^{1}$ \\ ${ }^{1}$ Tomsk Polytechnic University, 634050, Tomsk, Russia
}

\begin{abstract}
A diesel generator set working at variable speed to save fuel is studied. A description is provided of a laboratory bench for conducting experimental studies of a variable speed diesel generator set. Its component parts are described, and its technical characteristics are given.
\end{abstract}

\section{Introduction}

Russia has decentralized power supply zones with the greatest area in the world. They encompass about $70 \%$ of the country's territory, and house, according to different estimates, up to 20 million people. Most of these territories are located in areas with severe weather conditions - Siberia, the Far East, and the Far North. Traditionally, small-scale power generation sets have been used to supply consumers in decentralized zones with power - small power plants powering an autonomous electrical grid in one or several nearby communities. Most small-scale power plants working in various regions of Russia today have a host of similar problems, mostly due to significant wear of primary power plant equipment, a sharp lack of investment resources, difficult and expensive conditions of freight transportation, isolation from supply centers and maintenance services, etc. As the source for autonomous power supply systems, they have some clear advantages and wellknown disadvantages, namely: high consumption of fossil fuels for the production of one $\mathrm{kWh}$ of electric power, environmental pollution, etc. However, no adequate replacement is available.

One of the most promising directions in improving energy efficiency of local power supply systems is using renewable energy sources in the regional energy balance and optimizing the operating modes of primary energy equipment. Weather and geographic characteristics of the decentralized zones in question make it practically possible to use only wind and solar energy out of all types of renewable energy sources. Since electric power consumers need an uninterruptible power supply, hybrid power plants on the basis of diesel generator sets [1-3] are the most promising way to build autonomous power supply

\footnotetext{
*Corresponding author: serob@tpu.ru
} 
systems. One of the technical solutions to increasing the efficiency of autonomous power supply systems is changing the DGS operating mode from constant speed to variable speed, optimized according to the size of the electric load [4].

\section{Diesel generator sets operating at variable speed}

As stated above, the energy efficiency of a DGS can be increased significantly by changing the operating mode of the diesel engine from constant to variable speed and by using specialized regulators for controlling the plant [5]. A structural diagram of such a diesel generator set (DGS) is shown in Fig.1.

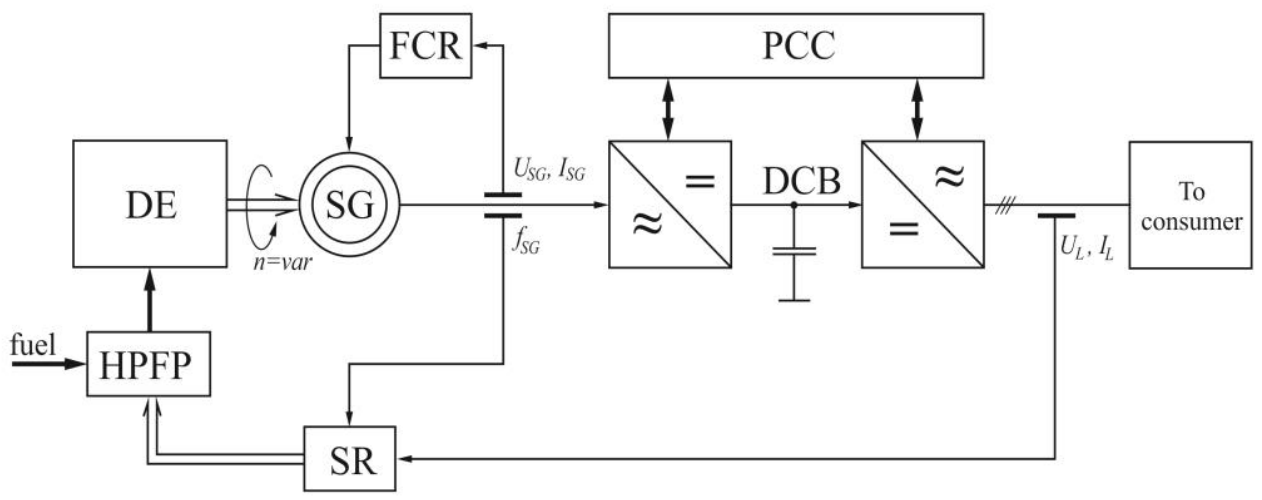

Fig. 1. Variable speed DGS structural diagram: DE - diesel engine; PCC - power converter controller; SR - speed regulator; FCR - field current regulator; SG - synchronous generator; HPFP high-pressure fuel pump; DCB - direct current bus.

\section{Laboratory bench}

A laboratory bench was developed and manufactured in order to conduct experimental research on variable speed DGSs. A key development requirement was providing high level of automation for the control flow of bench components, and for control and recording of measured variables.

Development of the structural and functional design of the laboratory bench was conducted in view of the following technical requirements: the possibility of modeling static and dynamic DGS modes of operation for all main parameters of the operating mode; use of the modular construction principle, which allows for simple attachment/detachment of separate components from the power plant; satisfying all mandatory fire, environmental, and electrical safety regulations; convenience in use and maintenance; the possibility of further modernization of the bench.

The structural design of the laboratory bench for studying the operating modes of variable speed DGSs is presented in Fig. 2, and its appearance is in Fig. 3.

The laboratory bench is based on the Kipor (China) KDE12EA3 diesel power plant [6]. The following changes were made in order to conduct experimental studies of the KDE12EA3 diesel power station: the fuel supply system to the diesel engine high-pressure pump and the air-intake system were modified; the drive component of the fuel pump final element was developed; a new synchronous generator excitation system was installed; an intake system for moving exhaust fumes outside of the laboratory space was fitted. 
A volumetric flow meter, for which the DARCONT OM 004A precision pressurized microrheometer with oval rotors was selected, was installed into the fuel line in order to receive a data signal on the DGS fuel consumption.

The BOSCH 028-0218 037 calorimetric film mass airflow sensor is used as the intake flowmeter. The G $3 / 4$ Water Flow Sensor TEM01071B rotor flowmeter is used for measuring the volumetric flow rate of cooling liquid. Semiconductor temperature probes and various types of thermal converters are used to control water temperature in the inlet manifold, cooling liquid, and diesel engine exhaust fumes, depending on the range of measured temperature values. The BOSCH 0261210113 variable inductance transducer, installed on the engine flywheel case, is used to measure the diesel engine shaft speed.

The synchronous generator excitation system developed within the framework of this project ensures that the regulation range for field current is from $0 . .5 \mathrm{~A}$ at a field voltage of up to $150 \mathrm{~V}$.

In order to measure immediate values of electrical variables, currents and voltages, the relevant sensors are installed in the bench. Current sensors were built on the basis of Honeywell sensor CSNB-131.

The in-line simulation stand (ILSS) of an autonomous electrical supply unit makes it possible to simulate three-phase symmetrical and asymmetrical loads on the unit within the range of $0-15 \mathrm{~kW}$ in increments of $0.25 \mathrm{~kW}$ in manual control mode, as well as to measure the load according to set parameters.

The data measuring system, which includes the data collection system (DCS) and personal computer (PC) with necessary software, plays an important role in the laboratory bench. The data collection system is based on modular devices with an Agilent Technology USB interface.

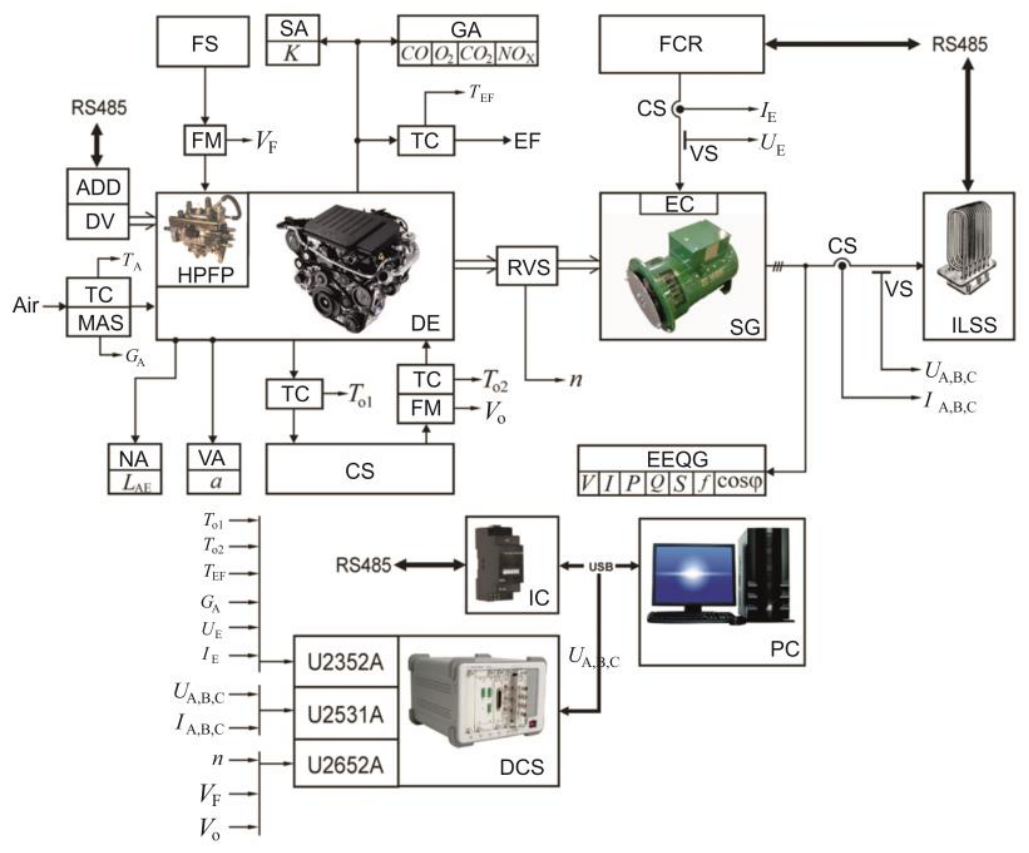

Fig. 2. The structural design of the laboratory bench: EEQG - Electrical energy quality gauge; GA gas analyzer; DE - diesel engine; SA - smoke analyzer; MAS - mass airflow sensor; RVS - rotation velocity sensor; DV - drive controller; EC - exciting coil; EF - exhaust fumes; IC - interface converter; PC - personal computer; ADD - fuel pump actuating device drive; FM - flow meter; FCR - generator field current regulator; SG - synchronous generator; CS - cooling system; ILSS - in-line simulation stand of an autonomous consumer load; DCS - data collection system; HPFP - high 
pressure fuel pump; TC - thermal converter (temperature sensor); FS - fuel system; CS - current sensor; VS - voltage sensor.

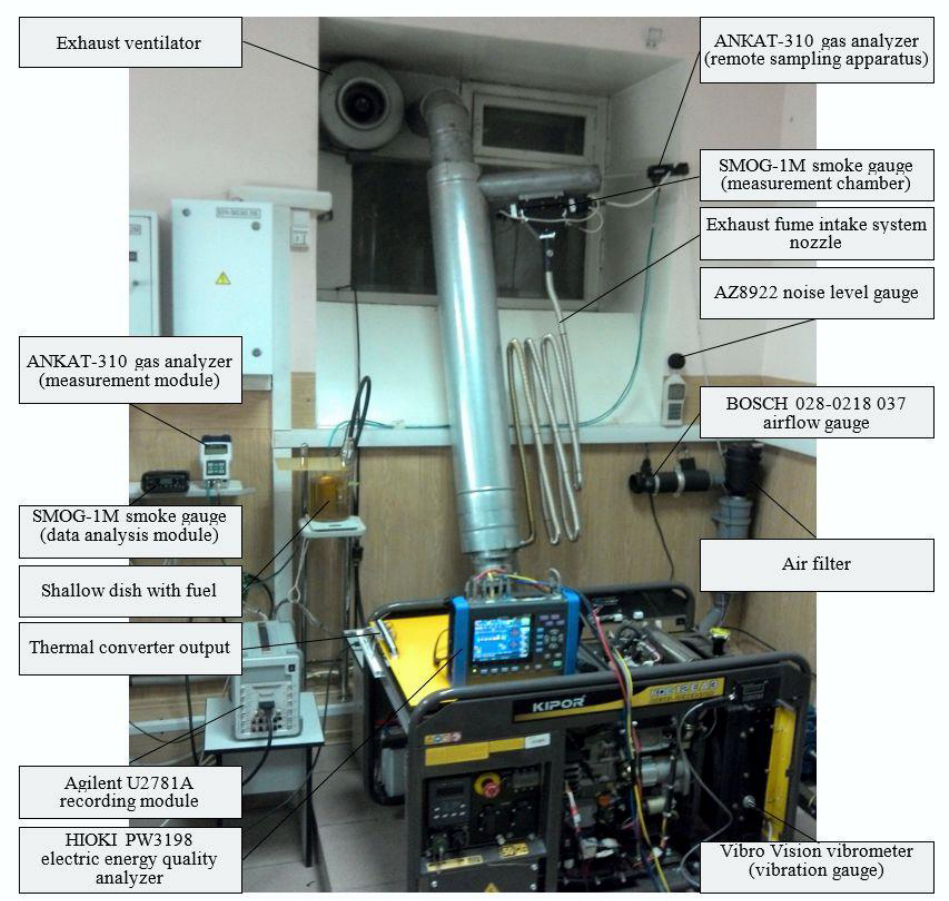

Fig. 3. Appearance of the laboratory stand.

\section{Conclusion}

The developed laboratory bench made it possible to conduct all of the necessary experimental research on proving the efficiency of changing the DGS operating mode from constant to variable speed and determining the areas for regulating the electrical unit through its operating modes.

\section{References}

1. Y. Sarsikeev, B. Lukutin, D. Lyapunov, M. Surkov, S. Obuhov, Adv. Mater. Res. 953954, 529 (2014)

2. B. Lukutin, E. Shandarova, D. Matukhin, A. Makarova, I. Fuks, IOP Conf. Ser.: Mater. Sci. Eng.. 124 (2016)

3. B. Lukutin, E. Shandarova, A. Makarova, I. Shvartsman, IOP Conf. Ser.: Mater. Sci. Eng. 127, 012005 (2016)

4. D. Wang, C. Nayar, C. Wang, 2nd IEEE International Symposium on Power Electronics for Distributed Generation Systems, 1 (2010)

5. Y. Zhang, S. Li, G. Lu, Y. Zhou, International Conference on Systems and Informatics, 619 (2012)

6. Kipor Power Co Power plants Available on: http://kipor-power.ru/catalog/ [accessed 25.11.2016] 